\title{
Adherence in a pragmatic randomized controlled trial on prophylactic iron supplementation during pregnancy in Maputo, Mozambique
}

\author{
Bright I Nwaru 1,2,* Graça Salomé ${ }^{3}$, Fatima Abacassamo ${ }^{4}$, Orvalho Augusto 4 , \\ Julie Cliff ${ }^{4}$, Cesar Sousa ${ }^{4}$, Elena Regushevskaya ${ }^{5}$, Saara Parkkali ${ }^{5}$ and Elina Hemminki ${ }^{5}$ \\ ${ }^{1}$ Centre for Population Health Sciences, The University of Edinburgh, Medical School, Doorway 3, Teviot Place, \\ Edinburgh EH8 9AG, UK: ${ }^{2}$ School of Health Sciences, University of Tampere, Tampere, Finland: ${ }^{3}$ Department of \\ Physiological Sciences, Eduardo Mondlane University, Maputo, Mozambique: ${ }^{4}$ Department of Community Health, \\ Eduardo Mondlane University, Maputo, Mozambique: ${ }^{5}$ National Institute for Health and Welfare, Health Services \\ and Policy Research, Helsinki, Finland
}

Submitted 13 September 2013: Final revision received 17 May 2014: Accepted 4 June 2014: First published online 7 July 2014

\begin{abstract}
Objective: Assessing the level of adherence and its determinants is important in appraising the overall effectiveness of trials. The present study aimed to evaluate the extent of adherence and its determinants in a pragmatic randomized controlled trial of Fe prophylaxis during pregnancy in Maputo, Mozambique.

Design: A pragmatic randomized controlled trial.

Setting: Two health centres ( $1^{\circ}$ de Maio and Machava) in Maputo, Mozambique. Subjects: Pregnant women ( $\geq 12$ weeks' gestation, $\geq 18$ years old, non-high-risk pregnancy; $n$ 4326) attending prenatal care consultations at two health centres were randomized to receive routine Fe ( $n$ 2184; $60 \mathrm{mg}$ ferrous sulfate plus $400 \mu \mathrm{g}$ folic acid daily throughout pregnancy) or selective Fe ( $n$ 2142; screening and treatment for anaemia and daily intake of $1 \mathrm{mg}$ folic acid).

Results: The level of adherence was $79 \%$ for having two or more visits, $53 \%$ for adequate prenatal care and $67 \%$ for complete intake of $\mathrm{Fe} /$ folic acid tablets during the trial. The correlation between the adherence measures ranged between $0 \cdot 151$ and 0.739 . Adherence did not differ by trial arm, but there were centre differences in adequate prenatal visits and intake of tablets. Older women ( $>20$ years) and those with a history of abortion were more likely to achieve greater adherence, whereas an increased number of previous births decreased the likelihood of adherence. HIV positivity decreased the likelihood of adherence in one trial centre and increased it in the other.

Conclusions: The variation in adherence by trial centre, women's characteristics and outcome measures suggests that adherence in trials fully depends on participants' behaviour and can be increased by paying attention to contextual factors.
\end{abstract}

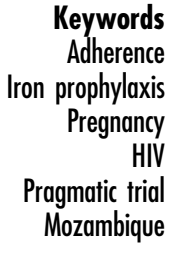

Adherence in trials is important because it can serve both as an indicator of the success of the intervention and as a predictor of study outcomes ${ }^{(1-3)}$. Adherence is generally defined as the extent to which a patient follows advice regarding health, such as taking medication, modifying risky habits and keeping scheduled medical appointments ${ }^{(1,3)}$. Extensive research has been undertaken to study the level of adherence and its impact on health outcomes in trials of various health interventions. In developing country settings, most studies on trial adherence have focused on antiretroviral therapy for $\mathrm{HIV}^{(4-6)}$.

There are however limited data on the extent of adherence in trials of interventions other than HIV therapy in developing countries. In these settings, health-care systems are inadequate, with several structural difficulties that impede health programme implementation and accessibility ${ }^{(7,8)}$. Consequently, achieving adequate follow-up of study participants and ensuring their optimal adherence to medications and the trial protocol are challenging.

Fe-deficiency anaemia remains common in many developing countries ${ }^{(9-11)}$. While prophylactic Fe supplementation has been shown to ameliorate Fe-deficiency anaemia in these settings ${ }^{(12)}$, its effect on the mother and child has so far yielded mixed findings ${ }^{(5,13)}$. There is evidence that Fe may increase the incidence of infections ${ }^{(13-15)}$, and this heightens the concern about routine Fe supplementation in malaria-endemic and HIV-prone developing countries. We set out to evaluate the effects of prophylactic Fe 
supplementation during pregnancy on maternal and child health in Maputo, Mozambique, a malaria-endemic and HIV-prevalent setting ${ }^{(13,16)}$. Specifically, we carried out a pragmatic randomized controlled trial comparing routine Fe prophylaxis (i.e. routine Fe supplementation from the first prenatal visit until delivery) $v$. selective Fe prophylaxis (i.e. screening for anaemia and Fe supplementation only to those found to be anaemic) during pregnancy ${ }^{(13,16)}$. Pragmatic trials are useful for comparing and informing choices between different treatment policies and are more suitable to study effects in normal clinical practice. In these types of trial design, placebo and blinding are not customary $^{(17-19)}$. The trial provided us with an opportunity to learn more about adherence in this setting.

An objective of the trial was to evaluate whether the two Fe administration policies are feasible in an ordinary health-care setting. Evaluating the level of adherence to trials of $\mathrm{Fe}$ supplementation and assessing potential determinants of adherence may constitute a key step in ascertaining the effectiveness of prophylactic Fe supplementation $^{(20)}$. Several studies in real life have shown that maternal educational status, age, socio-economic status, forgetfulness, perceived side-effects of medications, medication delivery mechanisms, nutritional status and risky behaviours such as smoking and alcohol intake were some of the main determinants of adherence to Fe or other multivitamin supplementation, particularly in developing country settings ${ }^{(20-23)}$. The aim of the present paper was to examine the extent of participants' adherence to the trial and to assess the factors that may influence adherence.

\section{Methods}

\section{Study design and participants}

The details of the PROFEG Trial have been described elsewhere $^{(13,16)}$. The trial was designed as a pragmatic randomized trial comparing two Fe administration policies on maternal and child health in two health centres $\left(1^{\circ}\right.$ de Maio and Machava) in Maputo: routine $\mathrm{Fe}$ (Fe prophylaxis from the first to the last prenatal visit) $v$. selective Fe (screening and treatment for anaemia). Women who were not at high obstetric risk and those aged 18 years and older were included in the study. Altogether, 2184 women were randomized to the routine Fe group and 2142 women to the selective Fe group. The routine Fe group received 30 tablets (supply of one month) of $60 \mathrm{mg}$ elemental Fe as ferrous sulfate plus $400 \mu \mathrm{g}$ folic acid per day, while those in the selective Fe group received 30 tablets of $1 \mathrm{mg}$ folic acid per day, calculated to last to the next visit; the recommended frequency of visits was once per month.

At each visit, the women were instructed and encouraged to take the Fe/folic acid tablets they were given. The $\mathrm{Hb}$ of women in the selective Fe group was measured at each visit using a rapid $\mathrm{Hb}$ measure, HemoCue ${ }^{\circledR} \mathrm{Hb} 201+$ (Hemocue AB, Ängelholm, Sweden). If their Hb level was below the cut-off of $<9 \mathrm{~g} / \mathrm{l}$, they received a monthly double dose of $\mathrm{Fe}(60 \mathrm{mg}+60 \mathrm{mg})$ for the treatment of anaemia. The tablets were given in a plastic bag with the drug's name and dose on it.

Ethical approval for the study was obtained from the Mozambique Ministry of Health Ethics Committee and a positive statement was obtained from the National Institute for Health and Welfare, Helsinki, Finland. The trial is registered at ClinicalTrials.gov, number NCT00488579 (June 2007). The first women were randomized to the trial proper between April 2007 and March 2008. The pilot was carried out between November 2006 and March 2008. The 3-month lag was due to technical difficulties in completing the trial registration.

Data collections for the study were done using standard study data forms involving three methods: (i) study nurses abstracted data from mothers' maternity cards; (ii) study nurses asked women additional questions at the time of the prenatal visits; and (iii) researchers later collected birth data from hospital birth records. Only data during pregnancy are used in the current paper. The study women were identified by the colour of the identification card stapled to their maternity card.

\section{Adberence}

Three measures of adherence were used: (i) acceptable number of prenatal visits; (ii) adequate prenatal visits index; and (iii) adequacy of intake of Fe/folic acid tablets during the trial. Women having two or more visits (including the recruitment visit) were categorized as having an acceptable number of visits. An adequate prenatal visits index was calculated by using the Adequacy of Prenatal Care Utilization (APNCU) index ${ }^{(24)}$. The APNCU index takes into account the gestational age at the initiation of care, the number of expected prenatal care visits and the number of observed visits. Here we categorized the adequate prenatal visits index into two: inadequate care (i.e. started prenatal visits after the 5th month or $\leq 50 \%$ of expected visits made) $v$. adequate care (i.e. started prenatal visits before or at the 5 th month and $>50 \%$ of expected visits made). The information on prenatal visits was obtained from the nurses' confirmation of a visit recorded on mothers' maternity cards.

Adequate adherence with regard to intake of Fe/folic acid tablets was defined as the intake of tablets reported at every visit attended by the woman. The woman was asked the following questions at each visit: 'Did you take the tablets during the past week?', with response options of 'regularly', 'sometimes yes and sometimes no' and 'no'. Women answering 'regularly' at each visit attended were defined as compliant. Women taking the Fe tablets were not differentiated from those taking the folic acid tablets in this question.

\section{Statistical analysis}

Women who were at 34 weeks' gestation or more at the recruitment visit ( $n$ 134) were excluded from all analyses, 
as most can be expected to have given birth before they could return for the next follow-up visit. Descriptive analysis was done using Pearson's $\chi^{2}$ or Fisher's exact test. The bivariate correlations between the adherence measures were analysed using Pearson's correlations.

We applied logistic regression to study the determinants of adherence. The covariates studied were maternal age, previous births, history of abortion (induced or spontaneous), history of stillbirth and HIV status at enrolment. Each of the covariates was independently studied in a bivariate analysis in relation to each outcome. To examine the most important determinants of adherence, we applied stepwise logistic regression by including together all the variables that achieved a $P$ value of $\leq 0.20$ in the bivariate association with each of the adherence measures. All the variables that remained at the last stage of the stepwise model were simultaneously adjusted. The estimates for the determinants of adherence are presented as odds ratios accompanied by their $95 \%$ confidence intervals. Statistical significance was taken as $P<0 \cdot 05$. The STATA 11 statistical software package was used for the analyses.

\section{Results}

Of the 4326 women recruited to the trial, 2184 were randomly allocated to the routine Fe group and 2142 to the selective Fe group. After exclusion of the 134 women who were at 34 weeks' gestation or more at enrolment, 2126 and 2066 women were in the routine and selective Fe groups, respectively. In each study centre, the distribution of the background characteristics was comparable between the two groups (Table 1). Women in the Machava study centre were significantly older, more likely to have HIV infection at enrolment, had more previous births and were more likely to have a stillbirth than women in the $1^{\circ}$ de Maio centre (data not shown).

Table 2 compares the adherence measures between the routine and selective Fe groups in each study centre. Most women (at least $92 \%$ of all women) had two or more prenatal visits during the trial period and about half had adequate prenatal care. Most women took the Fe/folic acid tablets regularly at each follow-up visit, but $67 \%$ of all women had regular intake of tablets throughout all visits. Each adherence measure was equally distributed between the trial groups in each centre. The number of prenatal visits was not statistically significantly different between the centres, but women attending the Machava study centre were more likely to have an adequate prenatal visits index than those from the $1^{\circ}$ de Maio study centre. Women attending the $1^{\circ}$ de Maio study centre were more likely to take the tablets than women who attended the Machava study centre.

The overall correlation coefficient between the number of visits and regular intake of tablets was low (0.151), while between an adequate prenatal visits index and regular intake of tablets, it was $0 \cdot 203$ (Table 3). The correlation between number of visits and adequacy of prenatal care seemed to measure the same thing, with a correlation coefficient of 0.739 (Table 3).

Table 4 shows the results of the bivariate analysis between each studied covariate and having two or more visits during the trial, for the two study centres combined and stratified by centre. Combining study centres, women $\geq 30$ years old were more likely to have two or more prenatal visits compared with women aged $\leq 20$ years. These results were similar in the two study centres when taken separately. Combining the study centres, women having had one previous birth were less likely to have two or more visits when compared with women who had no previous birth. These results were similar in the $1^{\circ}$ de Maio centre but differed in the Machava centre, so that having two or more previous births increased the likelihood of having two or more visits. HIV positivity at recruitment was associated with less likelihood of having two or more visits. Having a previous abortion (induced or spontaneous) was positively associated with having two or more prenatal visits. Previous history of stillbirth was not statistically significantly associated with having two or more visits. The stepwise regression model examined the important determinants of having two or more visits while adjusting for the covariates. According to the model, increasing maternal age and having previous abortions increased the likelihood of having two or more visits, while having one or more previous births and HIV positivity decreased the likelihood (Table 4).

Table 5 shows the results of the associations between the covariates and the adequate prenatal visits index, for the two study centres combined and stratified by centre. In the Machava centre separately and in the study centres combined, women $\geq 30$ years old were more likely to have an adequate prenatal visits index compared with women aged $\leq 20$ years. When combining the study centres, women having had one previous birth were less likely to have an adequate prenatal visits index compared with women who had no previous birth. These results were similar in both study centres. HIV positivity at recruitment was associated with less likelihood of having an adequate prenatal visits index in both centres combined and each centre separately. Having had a previous abortion (induced or spontaneous) was positively associated with having adequate prenatal visits in the two centres combined and in the Machava centre but not the $1^{\circ}$ de Maio centre separately. Previous history of stillbirth was not statistically significantly associated with the adequate prenatal visits index. In the stepwise regression model and after adjustments, increasing maternal age and having previous abortions increased the likelihood of an adequate prenatal visits index, while having one or more previous births and HIV positivity decreased the likelihood (Table 5).

Table 6 shows the results of the associations between each studied covariate and regular intake of tablets during 
Table 1 Characteristics of women by trial arm and study centre in the PROFEG Trial, a pragmatic randomized controlled trial of iron prophylaxis during pregnancy in Maputo, Mozambique

\begin{tabular}{|c|c|c|c|c|c|c|c|c|c|c|c|c|}
\hline \multirow[b]{3}{*}{ Characteristic } & & & \multicolumn{4}{|c|}{$1^{\circ}$ de Maio } & \multirow[b]{3}{*}{$P$ value* } & \multicolumn{4}{|c|}{ Machava } & \multirow[b]{3}{*}{$P$ value } \\
\hline & \multicolumn{2}{|c|}{ All (n 4192) } & \multicolumn{2}{|c|}{ Selective ( $n$ 1318) } & \multicolumn{2}{|c|}{ Routine (n 1350) } & & \multicolumn{2}{|c|}{ Selective ( $n$ 748) } & \multicolumn{2}{|c|}{ Routine ( $n 776)$} & \\
\hline & $n$ & $\%$ & $n$ & $\%$ & $n$ & $\%$ & & $n$ & $\%$ & $n$ & $\%$ & \\
\hline Maternal age (years) & & & & & & & 0.342 & & & & & 0.141 \\
\hline$\leq 20$ & 1140 & $27 \cdot 2$ & 366 & $27 \cdot 8$ & 415 & $30 \cdot 7$ & & 179 & 23.9 & 180 & 23.2 & \\
\hline $21-25$ & 1555 & $37 \cdot 1$ & 526 & 39.9 & 490 & $36 \cdot 3$ & & 267 & $35 \cdot 7$ & 272 & $35 \cdot 1$ & \\
\hline $26-29$ & 734 & 17.5 & 209 & $15 \cdot 9$ & 219 & $16 \cdot 2$ & & 154 & $20 \cdot 6$ & 152 & $19 \cdot 6$ & \\
\hline$\geq 30$ & 730 & 17.4 & 204 & $15 \cdot 4$ & 214 & $15 \cdot \overline{9}$ & & 141 & 18.9 & 171 & $22 \cdot 0$ & \\
\hline Noo information & 33 & 0.8 & 13 & 1.0 & 12 & 0.9 & & 7 & 0.9 & 1 & 0.1 & \\
\hline Previous births & & & & & & & 0.38 & & & & & 0.578 \\
\hline 0 & 1328 & 31.7 & 428 & 32.5 & 475 & $35 \cdot 2$ & & 202 & $27 \cdot 0$ & 223 & 28.7 & \\
\hline 1 & 1326 & 31.6 & 432 & $32 \cdot 8$ & 436 & $32 \cdot 3$ & & 237 & $31 \cdot 7$ & 221 & 28.5 & \\
\hline$\geq 2$ & 1526 & $36 \cdot 4$ & 454 & 34.4 & 437 & $32 \cdot 4$ & & 306 & 40.9 & 329 & $42 \cdot 4$ & \\
\hline No information & 12 & 0.3 & 4 & 0.3 & 2 & 0.1 & & 3 & 0.4 & 3 & 0.4 & \\
\hline HIV infection & & & & & & & 0.321 & & & & & 0.612 \\
\hline No & 3350 & 79.9 & 1060 & $80 \cdot 4$ & 1106 & 81.9 & & 577 & $77 \cdot 1$ & 607 & 78.2 & \\
\hline Yes & 842 & $20 \cdot 1$ & 258 & $19 \cdot 6$ & 244 & $18 \cdot 1$ & & 171 & 22.9 & 169 & $21 \cdot 8$ & \\
\hline Previous abortion $†$ & & & & & & & 0.368 & & & & & 0.927 \\
\hline No & 3643 & $86 \cdot 9$ & 1163 & $88 \cdot 2$ & 1172 & $86 \cdot 8$ & & 644 & $86 \cdot 1$ & 664 & 85.6 & \\
\hline Yes & 537 & $12 \cdot 8$ & 151 & $11 . \overline{5}$ & 176 & 13.0 & & 101 & 13.5 & 109 & 14.0 & \\
\hline No information & 12 & 0.3 & 4 & 0.3 & 2 & 0.2 & & 3 & 0.4 & 3 & 0.4 & \\
\hline Previous stillbirth & & & & & & & 0.542 & & & & & 0.532 \\
\hline No & 3864 & $92 \cdot 2$ & 1244 & 94.4 & 1262 & 93.5 & & 661 & 88.4 & 699 & $90 \cdot 1$ & \\
\hline Yes & 312 & 7.5 & 71 & 5.4 & 86 & $6 \cdot 4$ & & 82 & $11 \cdot 0$ & 73 & 9.4 & \\
\hline No information & 14 & 0.3 & 3 & 0.2 & 2 & 0.1 & & 5 & 0.6 & 4 & 0.5 & \\
\hline
\end{tabular}

${ }^{*} P$ value from Fisher's exact test (for cells with $\leq 5$ observations) or $x^{2}$ test of the difference in background characteristics between the routine and selective Fe groups in each study centre.

tIncludes induced and spontaneous abortions.

Table 2 Adherence to the trial by trial arm and study centre* in the PROFEG Trial, a pragmatic randomized controlled trial of iron prophylaxis during pregnancy in Maputo, Mozambique

\begin{tabular}{|c|c|c|c|c|c|c|c|c|c|c|c|c|}
\hline \multirow[b]{3}{*}{ Covariates } & \multicolumn{6}{|c|}{$1^{\circ}$ de Maio } & \multirow[b]{3}{*}{$P$ value } & \multicolumn{4}{|c|}{ Machava } & \multirow[b]{3}{*}{$P$ valuet } \\
\hline & \multicolumn{2}{|c|}{ All } & \multicolumn{2}{|c|}{ Selective } & \multicolumn{2}{|c|}{ Routine } & & \multicolumn{2}{|c|}{ Selective } & \multicolumn{2}{|c|}{ Routine } & \\
\hline & $n$ & $\%$ & $n$ & $\%$ & $n$ & $\%$ & & $n$ & $\%$ & $n$ & $\%$ & \\
\hline \multicolumn{7}{|l|}{ Number of visits $\ddagger$} & \multirow[t]{3}{*}{0.959} & & & & & \multirow[t]{3}{*}{0.458} \\
\hline$<2$ visits & 875 & $20 \cdot 9$ & 284 & 21.6 & 292 & 21.6 & & 141 & 18.9 & 158 & 20.4 & \\
\hline$\geq 2$ visits & 3317 & $79 \cdot 1$ & 1034 & 78.4 & 1058 & 78.4 & & 607 & $81 \cdot 1$ & 618 & $79 \cdot 6$ & \\
\hline \multicolumn{7}{|l|}{ Adequate prenatal visits index } & \multirow[t]{4}{*}{0.457} & & & & & \multirow[t]{4}{*}{$0 \cdot 158$} \\
\hline Inadequate & 1854 & $44 \cdot 2$ & 640 & $48 \cdot 6$ & 623 & $46 \cdot 2$ & & 290 & $38 \cdot 8$ & 301 & $38 \cdot 8$ & \\
\hline Adequate & 2234 & 53.3 & 635 & 48.2 & 682 & 50.5 & & 454 & 60.7 & 463 & 59.7 & \\
\hline No information & 104 & $2 \cdot 5$ & 43 & $3 \cdot 2$ & 45 & 3.3 & & 4 & 0.5 & 12 & 1.5 & \\
\hline \multicolumn{13}{|c|}{ Reported regular intake of tablets at each visit } \\
\hline 2nd visit ( $n$ 2949) & 2724 & $92 \cdot 4$ & 883 & $94 \cdot 1$ & 912 & 94.5 & 0.726 & 461 & $89 \cdot 2$ & 468 & 88.5 & \multirow{7}{*}{$\begin{array}{l}0.720 \\
0.898 \\
0.274 \\
0.409 \\
0.206\end{array}$} \\
\hline 3rd visit $(n 2146)$ & 1993 & 92.9 & 588 & 95.2 & 652 & $96 \cdot 3$ & 0.301 & 374 & 88.6 & 379 & 88.3 & \\
\hline 4 th visit $(n 1414)$ & 1317 & $93 \cdot 1$ & 381 & 95.7 & 402 & $97 \cdot 6$ & 0.144 & 266 & 89.9 & 268 & $87 \cdot 0$ & \\
\hline \multirow{2}{*}{\multicolumn{7}{|c|}{ Regular intake of tablets in all $\geq 2$ visits }} & 0.986 & 164 & $88 \cdot 7$ & 144 & $85 \cdot 7$ & \\
\hline & & & & & & & \multirow{3}{*}{0.631} & & & & & \\
\hline Noß & 1365 & $32 \cdot 6$ & 386 & $29 \cdot 3$ & 384 & 28.4 & & 280 & 37.4 & 315 & $40 \cdot 6$ & \\
\hline Yes & 2827 & 67.4 & 932 & $70 \cdot 7$ & 966 & 71.6 & & 468 & $62 \cdot 6$ & 461 & $59 \cdot 4$ & \\
\hline
\end{tabular}

$P$ values for the differences between the study centres: number of visits $(P=0.131)$; adequate prenatal visits index $(P<0.001)$; intake of tablets $(P<0.001)$. "Women ( $n$ 134) who were $\geq 34$ weeks' gestation were excluded.

$\dagger P$ value from Fisher's exact test (for cells with expected frequency $\leq 5$ ) or $x^{2}$ test of difference in compliance between the routine and selective Fe groups in each study centre.

łIncluding recruitment visit.

$\S$ Includes those who missed regular intake at least once.

the trial for the two study centres combined and stratified by centre. Women $\geq 30$ years old were more likely to have had a regular intake of tablets compared with women aged $\leq 20$ years in both centres combined and in the
Machava centre separately. Combining the study centres, women having one previous birth were less likely to have had a regular intake of tablets compared with women who had had no previous birth, but having two or more 
Table 3 Bivariate Pearson correlations between the adherence measures in the PROFEG Trial, a pragmatic randomized controlled trial of iron prophylaxis during pregnancy in Maputo, Mozambique

\begin{tabular}{lccc}
\hline & Number of visits & $\begin{array}{c}\text { Adequate prenatal } \\
\text { visits index }\end{array}$ & $\begin{array}{c}\text { Regular intake of tablets } \\
\text { in all } \geq 2 \text { visits }\end{array}$ \\
\hline $\begin{array}{l}\text { Number of visits } \\
\text { Correlation coefficient }\end{array}$ & 1.000 & & \\
$P$ value & - & & \\
$\begin{array}{l}\text { Adequate prenatal visits index } \\
\quad \text { Correlation coefficient }\end{array}$ & 0.739 & 1.000 & 0.203 \\
$\quad P$ value & $<0.001$ & - & $<0.001$ \\
$\begin{array}{l}\text { Regular intake of tablets in all } \geq 2 \text { visits } \\
\quad \text { Correlation coefficient }\end{array}$ & 0.151 & 0.203 & 1.000 \\
$P$ value & $<0.001$ & $<0.001$ & - \\
\hline
\end{tabular}

Table 4 Determinants of two or more visits during the trial by study centre in the PROFEG Trial, a pragmatic randomized controlled trial of iron prophylaxis during pregnancy in Maputo, Mozambique

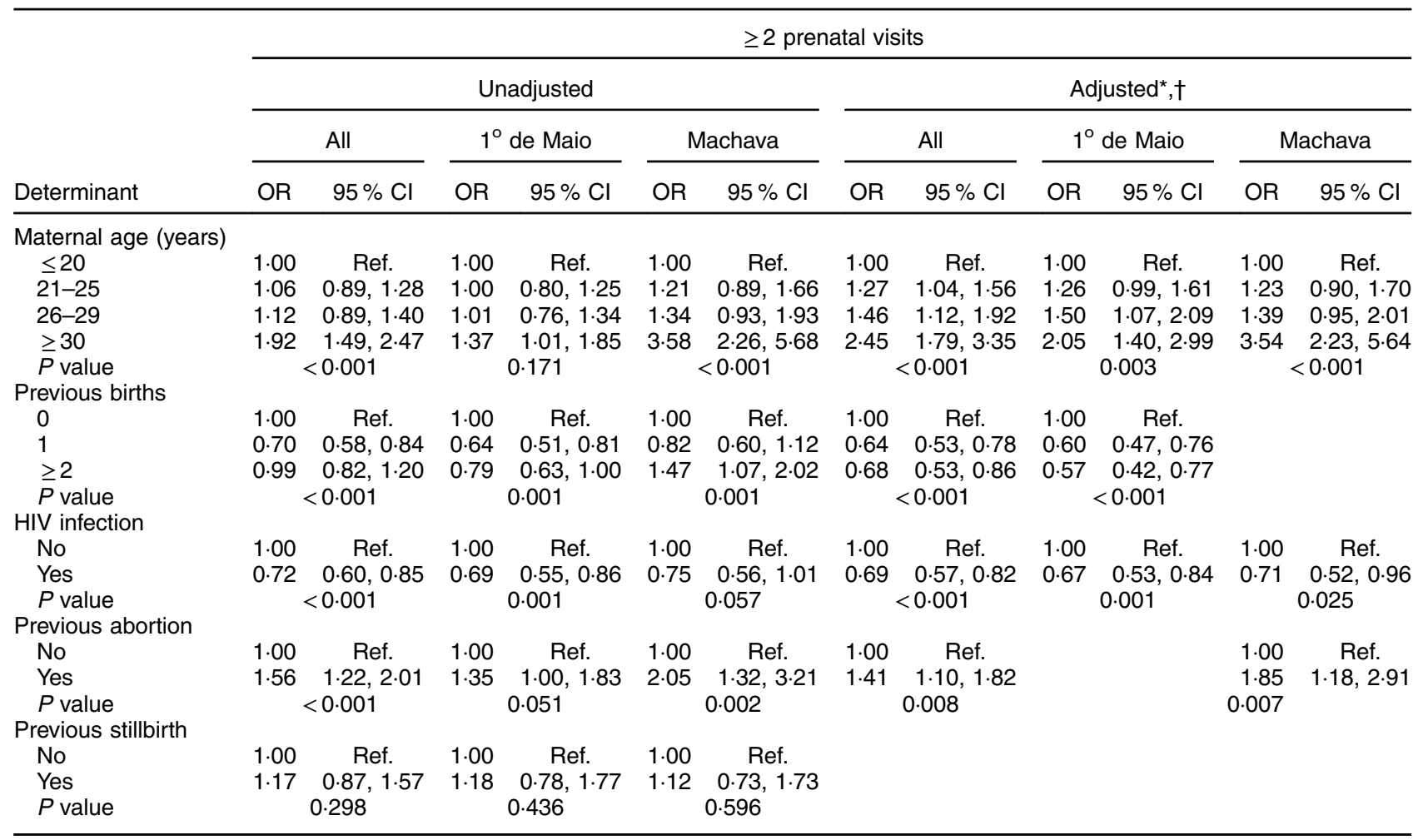

Ref., referent category.

*The determinants that achieved $P \leq 0.20$ in the unadjusted model were studied together in a stepwise regression model.

†Only estimates of the variables that remained in the last stage of the stepwise model are presented here after simultaneous adjustment.

previous births increased the likelihood of having had a regular intake of tablets in the Machava centre but not in $1^{\circ}$ de Maio centre separately. HIV positivity at recruitment was associated with less likelihood of having had a regular intake of tablets in the $1^{\circ}$ de Maio centre but increased the likelihood in the Machava centre. Having a previous abortion (induced or spontaneous) was positively associated with having a regular intake of tablets only in the $1^{\mathrm{o}}$ de Maio study centre. Previous history of stillbirth was not statistically significantly associated with a regular intake of tablets. In the stepwise regression model and after adjustment for the covariates, increasing maternal age increased the likelihood of having had a regular intake of tablets in both centres combined and in the Machava centre separately. Having one or more previous births decreased the likelihood of having had a regular intake of tablets only in the two centres combined. HIV positivity decreased the likelihood of having had a regular intake of tablets in the $1^{\circ}$ de Maio centre while it increased the likelihood in the Machava centre. Finally, having a previous abortion increased the likelihood of having had a regular intake of tablets only in the $1^{\circ}$ de Maio centre (Table 6). 
Table 5 Determinants of adequate prenatal visits index by study centre in the PROFEG Trial, a pragmatic randomized controlled trial of iron prophylaxis during pregnancy in Maputo, Mozambique

\begin{tabular}{|c|c|c|c|c|c|c|c|c|c|c|c|c|}
\hline \multirow[b]{4}{*}{ Determinant } & \multicolumn{12}{|c|}{ Adequate prenatal visits index } \\
\hline & \multicolumn{6}{|c|}{ Unadjusted } & \multicolumn{6}{|c|}{ Adjusted $^{*}, \dagger$} \\
\hline & \multicolumn{2}{|r|}{ All } & \multicolumn{2}{|c|}{$1^{\circ}$ de Maio } & \multicolumn{2}{|c|}{ Machava } & \multicolumn{2}{|r|}{ All } & \multicolumn{2}{|c|}{$1^{\circ}$ de Maio } & \multicolumn{2}{|c|}{ Machava } \\
\hline & OR & $95 \% \mathrm{Cl}$ & OR & $95 \% \mathrm{Cl}$ & OR & $95 \% \mathrm{Cl}$ & OR & $95 \% \mathrm{Cl}$ & OR & $95 \% \mathrm{Cl}$ & OR & $95 \% \mathrm{Cl}$ \\
\hline \multicolumn{13}{|c|}{ Maternal age (years) } \\
\hline$\leq 20$ & 1.00 & Ref. & 1.00 & Ref. & 1.00 & Ref. & 1.00 & Ref. & & & 1.00 & Ref. \\
\hline $21-25$ & 1.18 & $1.01,1.38$ & $1 \cdot 12$ & $0.93,1.36$ & 1.27 & $0.97,1.67$ & 1.50 & $1.26,1.78$ & & & 1.55 & $1 \cdot 14,2 \cdot 10$ \\
\hline $26-29$ & 1.00 & $0.83,1.20$ & 0.91 & $0.72,1.10$ & 1.08 & $0.79,1.46$ & 1.50 & $1 \cdot 19,1.88$ & & & 1.47 & $1.01,2.15$ \\
\hline $\begin{array}{l}\geq 30 \\
P \text { value }\end{array}$ & \multicolumn{2}{|c|}{$<0.001$} & \multicolumn{2}{|c|}{0.220} & \multicolumn{2}{|c|}{$<0.001$} & \multicolumn{2}{|c|}{$<0.001$} & & & $2 \cdot 83$ & $\begin{aligned} & 1.86,4.30 \\
&<0.001\end{aligned}$ \\
\hline \multicolumn{13}{|c|}{ Previous births } \\
\hline 0 & 1.00 & Ref. & 1.00 & Ref. & 1.00 & Ref. & 1.00 & Ref. & 1.00 & Ref. & 1.00 & Ref. \\
\hline 1 & 0.70 & $0.60,0.81$ & 0.66 & $0.54,0.80$ & 0.76 & $0.58,1.00$ & 0.61 & $0.52,0.72$ & 0.67 & $0.55,0.81$ & 0.65 & $0.48,0.87$ \\
\hline $\begin{array}{l}\geq 2 \\
P \text { value }\end{array}$ & 0.76 & $\begin{aligned} & 0.66,0.89 \\
< & 0.001\end{aligned}$ & 0.63 & $\begin{aligned} & 0.52,0.76 \\
< & 0.001\end{aligned}$ & 0.96 & $\begin{array}{l}0.74,1.23 \\
0.089\end{array}$ & 0.52 & $\begin{aligned} & 0.43,0.64 \\
< & 0.001\end{aligned}$ & 0.63 & $\begin{aligned} & 0.52,0.77 \\
< & 0.001\end{aligned}$ & $\begin{array}{c}0.61 \\
0.005\end{array}$ & $0.43,0.86$ \\
\hline \multicolumn{13}{|l|}{ HIV infection } \\
\hline No & 1.00 & Ref. & 1.00 & Ref. & 1.00 & Ref. & 1.00 & Ref. & 1.00 & Ref. & 1.00 & Ref. \\
\hline $\begin{array}{l}\text { Yes } \\
P \text { value }\end{array}$ & 0.79 & $\begin{array}{l}0.68,0.92 \\
0.003\end{array}$ & 0.79 & $\begin{array}{l}0.65,0.97 \\
0.021\end{array}$ & 0.75 & $\begin{array}{l}0.58,0.95 \\
0.019\end{array}$ & 0.77 & $\begin{array}{l}0.66,0.90 \\
0.001\end{array}$ & 0.83 & $\begin{array}{l}0.68,1.01 \\
0.057\end{array}$ & $0 \cdot 72$ & $\begin{array}{l}0.56,0.93 \\
0.011\end{array}$ \\
\hline \multicolumn{13}{|c|}{ Previous abortion } \\
\hline No & 1.00 & Ref. & 1.00 & Ref. & 1.00 & Ref. & 1.00 & Ref. & & & 1.00 & Ref. \\
\hline $\begin{array}{l}\text { Yes } \\
P \text { value }\end{array}$ & 1.35 & $\begin{array}{l}1.12,1.63 \\
0.002\end{array}$ & $1 \cdot 18$ & $\begin{array}{l}0.93,1.49 \\
0.178\end{array}$ & 1.66 & $\begin{array}{l}1 \cdot 21,2 \cdot 28 \\
0.002\end{array}$ & $1 \cdot 21$ & $\begin{array}{l}1.00,1.47 \\
0.050\end{array}$ & & & 1.52 & $\begin{array}{l}1 \cdot 10,2 \cdot 10 \\
0.012\end{array}$ \\
\hline \multicolumn{13}{|c|}{ Previous stillbirth } \\
\hline No & 1.00 & Ref. & 1.00 & Ref. & 1.00 & Ref. & & & & & & \\
\hline Yes & $1 \cdot 18$ & $0.93,1.50$ & 1.14 & $0.83,1.59$ & 1.09 & $0.78,1.54$ & & & & & & \\
\hline$P$ value & & 0.167 & & 0.451 & & 0.616 & & & & & & \\
\hline
\end{tabular}

Ref., referent category.

${ }^{*}$ The determinants that achieved $\mathrm{P} \leq 0.20$ in the unadjusted model were studied together in a stepwise regression model.

†Only estimates of the variables that remained in the last stage of the stepwise model are presented here after simultaneous adjustment.

\section{Discussion}

Adherence in the present study was measured by the number of prenatal visits, an adequate prenatal visits index and the complete intake of Fe/folic acid tablets. The level of adherence depended on the measure used to define it: $79 \%$ of women had at least two visits during the trial; $67 \%$ had had a regular intake of Fe/folic acid tablets in all visits; and only about half had an adequate prenatal visits index. Adherence did not differ by trial arm, but varied unsystematically by study centre. Older women ( $>20$ years) and those with a history of abortion were more likely to achieve greater adherence, whereas an increasing number of previous births decreased the likelihood of adherence. HIV positivity either decreased or increased the likelihood of adherence, depending on the trial centre.

We found only two previous trials that examined adherence and its determinants in Fe prophylaxis during pregnancy in developing country settings. Kulkarni et $a l .{ }^{(20)}$ measured adherence by the percentage of total eligible dose of $\mathrm{Fe} /$ folic acid consumed during pregnancy through the postpartum and found that only $49 \%$ of women who participated in an Fe prophylactic trial in
Nepal achieved high adherence (defined as being in the upper median of adherence). The level of adherence in that study was lower than the level observed in our study (67\%) with regard to complete intake of Fe/folic acid tablets. One of the key determinants of adherence in that particular study was maternal age, which is comparable to our results, showing that older maternal age could influence greater adherence to the trial protocol.

In a trial in the Philippines, Lutsey et $a l^{(21)}$ defined adherence as the timeliness of the first prenatal visit, visits per month and pill count, and found that only $40 \%$ of women achieved the expected adherence in terms of pill count, which was also lower than the adherence achieved in our study using any of the indicators for adherence. In the Filipino study, married women were more likely to have greater adherence, while having more children was associated with lower adherence ${ }^{(21)}$. We did not study the influence of marital status on adherence, but the observed lower likelihood of adherence with an increasing number of children is comparable to our study.

Adherence did not differ by trial arm in our study. But the level of adherence with regard to adequacy of prenatal care and intake of tablets varied between the two study centres. 
Table 6 Determinants of regular intake of tablets during visits by study centre in the PROFEG Trial, a pragmatic randomized controlled trial of iron prophylaxis during pregnancy in Maputo, Mozambique

\begin{tabular}{|c|c|c|c|c|c|c|c|c|c|c|c|c|}
\hline \multirow[b]{4}{*}{ Determinant } & \multicolumn{12}{|c|}{ Regular intake of tablets during visits } \\
\hline & \multicolumn{6}{|c|}{ Unadjusted } & \multicolumn{6}{|c|}{ Adjusted $^{*}, \dagger$} \\
\hline & \multicolumn{2}{|r|}{ All } & \multicolumn{2}{|c|}{$1^{\circ}$ de Maio } & \multicolumn{2}{|c|}{ Machava } & \multicolumn{2}{|r|}{ All } & \multicolumn{2}{|c|}{$1^{\circ}$ de Maio } & \multicolumn{2}{|r|}{ Machava } \\
\hline & OR & $95 \% \mathrm{Cl}$ & OR & $95 \% \mathrm{Cl}$ & OR & $95 \% \mathrm{Cl}$ & OR & $95 \% \mathrm{Cl}$ & OR & $95 \% \mathrm{Cl}$ & OR & $95 \% \mathrm{Cl}$ \\
\hline \multicolumn{13}{|c|}{ Maternal age (years) } \\
\hline$\leq 20$ & 1.00 & Ref. & 1.00 & Ref. & 1.00 & Ref. & 1.00 & Ref. & & & 1.00 & Ref. \\
\hline $21-25$ & $1 \cdot 15$ & $0.98,1.35$ & 1.04 & $0.85,1.28$ & 1.44 & $1 \cdot 10,1 \cdot 89$ & $1 \cdot 26$ & $1.05,1.50$ & & & $1 \cdot 38$ & $1.05,1.81$ \\
\hline $26-29$ & 1.04 & $0.86,1.26$ & 0.98 & $0.76,1.27$ & 1.33 & $0.98,1.81$ & 1.18 & $0.94,1.49$ & & & 1.28 & $0.94,1.75$ \\
\hline $\begin{array}{l}\geq 30 \\
P \text { value }\end{array}$ & 1.55 & $\begin{aligned} & 1.26,1.90 \\
< & 0.001\end{aligned}$ & 1.28 & $\begin{array}{l}0.98,1.67 \\
0.284\end{array}$ & $2 \cdot 38$ & $\begin{aligned} & 1.72,3.29 \\
< & 0.001\end{aligned}$ & 1.77 & $\begin{aligned} & 1.37,2.29 \\
< & 0.001\end{aligned}$ & & & $2 \cdot 32$ & $\begin{aligned} & 1.68,3.21 \\
< & 0.001\end{aligned}$ \\
\hline \multicolumn{13}{|c|}{ Previous births } \\
\hline 0 & 1.00 & Ref. & 1.00 & Ref. & 1.00 & Ref. & 1.00 & Ref. & & & & \\
\hline 1 & 0.85 & $0.72,1.00$ & 0.82 & $0.67,1.00$ & 0.94 & $0.72,1.23$ & 0.78 & $0.66,0.93$ & & & & \\
\hline$\geq 2$ & 1.04 & $0.89,1.22$ & 0.96 & $0.78,1.18$ & 1.30 & $1.01,1.68$ & 0.81 & $0.66,0.99$ & & & & \\
\hline $\bar{P}$ value & & 0.033 & & 0.119 & & 0.022 & & 0.017 & & & & \\
\hline HIV infection & & & & & & & & & & & & \\
\hline No & 1.00 & Ref. & 1.00 & Ref. & 1.00 & Ref. & & & 1.00 & Ref. & 1.00 & Ref. \\
\hline Yes & 0.96 & $0.81,1.12$ & 0.74 & $0.60,0.91$ & 1.45 & $1 \cdot 12,1 \cdot 87$ & & & 0.74 & $0.60,0.91$ & 1.39 & $1.07,1.80$ \\
\hline$P$ value & & 0.574 & & 0.004 & & 0.004 & & & & 0.005 & & 0.013 \\
\hline \multicolumn{13}{|c|}{ Previous abortion } \\
\hline No & 1.00 & Ref. & 1.00 & Ref. & 1.00 & Ref. & & & 1.00 & Ref. & & \\
\hline Yes & 1.21 & $0.99,1.47$ & 1.34 & $1.03,1.76$ & $1 \cdot 10$ & $0.81,1.48$ & & & 1.34 & $1.03,1.76$ & & \\
\hline$P$ value & & 0.063 & & 0.032 & & 0.553 & & & & 0.032 & & \\
\hline \multicolumn{13}{|c|}{ Previous stillbirth } \\
\hline No & 1.00 & Ref. & 1.00 & Ref. & 1.00 & Ref. & & & & & & \\
\hline $\begin{array}{l}\text { Yes } \\
P \text { value }\end{array}$ & $1 \cdot 15$ & $\begin{array}{l}0.89,1.48 \\
0.283\end{array}$ & $1 \cdot 16$ & $\begin{array}{l}0.80,1.67 \\
0.431\end{array}$ & 1.30 & $\begin{array}{l}0.92,1.85 \\
0.142\end{array}$ & & & & & & \\
\hline
\end{tabular}

Ref., referent category.

*The determinants that achieved $P \leq 0.20$ in the unadjusted model were studied together in a stepwise regression model.

tOnly estimates of the variables that remained in the last stage of the stepwise model are presented here after simultaneous adjustment.

The variation by centre suggests that from the practical point of view, adherence can be influenced. While the determinants of adherence were in general similar between the study centres, the decreased likelihood of complete intake of $\mathrm{Fe} /$ folic acid tablets in $1^{\circ}$ de Maio and increased likelihood in Machava as a result of HIV positivity could highlight some differences in the health-care systems between the two centres with regard to handling of HIV cases or the way instructions or programmes regarding HIV testing are given. From our experience, $1^{\circ}$ de Maio was usually busier than Machava with regard to maternal health programmes undertaken and women seemed better followed up for their HIV in $1^{\circ}$ de Maio than in Machava.

As a critical measure for assessing the success of a trial $^{(1-3)}$, the failure of participants to adhere to instructions in a trial protocol would undermine the possibility of evaluating the overall effectiveness of a trial ${ }^{(1-3)}$. The level of adherence in a trial could also be a predictor of the outcomes in a trial ${ }^{(20)}$. Consequently, measuring and monitoring adherence in a trial and evaluating its potential determinants are important. Some of the indicators used to assess adherence in trials include following instructions regarding a medication regimen, behaviours regarding instructions on risky habit modification and keeping scheduled medical appointments ${ }^{(1,3)}$.
Clearly, each of the indicators used to assess adherence may be measuring different aspects of adherence, thus they may be providing distinctive information on the success of different aspects of a trial. Lutsey et al. observed correlation coefficients between 0.548 and 0.683 between the adherence indicators they studied (timeliness of first prenatal visit, visits per month and pill count $)^{(21)}$. In the current study, we measured adherence using three indicators: number of visits during the trial; adequacy of prenatal care; and complete intake of $\mathrm{Fe} /$ folic acid tablets during the trial. The correlation coefficients between these indicators ranged from 0.151 to 0.739 , which suggests that each indicator may be measuring a different aspect of adherence to the trial. Accordingly, studies should endeavour to evaluate adherence using different measures in order to gain a more comprehensive perspective on how the participants in a trial adhere to the different aspects of the trial protocol.

\section{Conclusion}

In the current pragmatic trial on Fe prophylaxis during pregnancy, women's adherence to the trial protocols with regard to number of prenatal visits and intake of $\mathrm{Fe} /$ folic acid tablets was above the 50th percentile. Key determinants 
of adherence were maternal age, number of previous births, HIV status and a history of abortion; consequently they should be taken into account in trials evaluating the effectiveness of prophylactic Fe supplementation during pregnancy in developing country settings. The observed centre differences in the level of adherence and its determinants may indicate that each trial centre should be carefully studied to understand the characteristics that may undermine or promote women's adherence to the trial protocol.

\section{Acknowledgements}

Financial support: The study was funded by two grants from the Academy of Finland (2004, grant number 210631; 2010, grant number 139191). The Academy of Finland had no role in the design, analysis or writing of this article. Conflict of interest: None. Authorship: B.I.N. and E.H. designed, analysed and wrote the paper. E.H. designed and was responsible for the conception of the PROFEG Trial. C.S., E.H., F.A., G.S., J.C., O.A. and S.P. participated in the planning of the PROFEG Trial and made substantial contribution in its execution, participated in interpretation of the results and critically reviewed the manuscript. E.R. and O.A. were responsible for data preparation and cleaning. Ethics of buman subject participation: Ethical approval for the study was obtained from the Mozambique Ministry of Health Ethics Committee and a positive statement was obtained from the National Institute for Health and Welfare, Helsinki, Finland. The trial is registered at ClinicalTrials.gov, number NCT00488579.

\section{References}

1. Osterberg L \& Blaschke T (2005) Adherence to medication. $N$ Engl J Med 353, 487-497.

2. Hays RD, Kravitz RL, Mazel RM et al. (1994) The impact of patient adherence on health outcomes for patients with chronic disease in the Medical Outcomes Study. $J$ Behav Med 17, 347-360.

3. Muyingo SK, Walker AS, Reid A et al. (2008) Patterns of individual and population-level adherence to antiretroviral therapy and risk factors for poor adherence in the first year of the DART Trial in Uganda and Zimbabwe. J Acquir Immune Defic Syndr 48, 468-475.

4. Ajose O, Mookerjee S, Mills EJ et al. (2012) Treatment outcomes of patients on second-line antiretroviral therapy in resource-limited settings: a systematic review and metaanalysis. AIDS 26, 929-938.

5. Rachlis BS, Mills EJ \& Cole DC (2011) Livelihood security and adherence to antiretroviral therapy in low and middle income settings: a systematic review. PLOS One 6, e18948.

6. Koethe JR, Chi BH, Megazzini KM et al. (2009) Macronutrient supplementation for malnourished HIV-infected adults: a review of the evidence in resource-adequate and resource-constrained settings. Clin Infect Dis 49, 787-798.
7. Chudi IP (2010) Healthcare problems in developing countries. Med Pract Rev 1, 9-11.

8. Razzak JA \& Kellermann AL (2002) Emergency medical care in developing countries: is it worthwhile? Bull World Health Organ 80, 900-905.

9. United Nations System Standing Committee on Nutrition (2004) Fifth Report on the World Nutrition Situation: Nutrition for Improved Development Outcomes. http://www. unsystem.org/scn/Publications/AnnualMeeting/SCN31/SCN5 Report.pdf (accessed October 2013).

10. McLean E, Cogswell M, Egli I et al. (2009) Worldwide prevalence of anaemia, WHO Vitamin and Mineral Nutrition Information System, 1993-2005. Public Health Nutr 12, 444-454.

11. Stoltzfus RJ, Mullanny L \& Black RE (2004) Iron deficiency anaemia. In Comparative Quantification of Health Risks: Global and Regional Burden of Disease Attributable to Selected Major Risk Factors, vol. 1, pp. 163-209 [M Ezzati, AD Lopez, A Rodgers et al., editors]. Geneva: WHO.

12. Peña-Rosas JP \& Viteri FE (2009) Effects and safety of preventive oral iron or iron + folic acid supplementation for women during pregnancy. Cochrane Database Syst Rev issue 4, CD004736.

13. Nwaru BI, Parkkali S, Abacassamo F et al. (2012) A pragmatic randomised controlled trial on routine iron prophylaxis during pregnancy in Maputo, Mozambique (PROFEG): rationale, design, and success. Matern Child Nutr (Epublication ahead of print version).

14. Prentice AM (2008) Iron metabolism, malaria, and other infections: what is all the fuss about? J Nutr 138, 2537-2541.

15. Gera T \& Sachdev HPS (2002) Effect of iron supplementation on incidence of infectious illness in children: systematic review. BMJ 325, 1142.

16. Parkkali S, Abacassamo F, Nwaru BI et al. (2013) Comparison of routine prenatal iron prophylaxis and screening and treatment for anaemia: pregnancy results and preliminary birth results from a pragmatic randomised controlled trial (PROFEG) in Maputo, Mozambique. BMJ Open 3, e001948.

17. MacPherson H (2004) Pragmatic clinical trials. Complement Ther Med 12, 136-140.

18. Roland M \& Torgerson DJ (1998) Understanding controlled trials: what are pragmatic trials? BMJ 316, 285.

19. Zwarenstein M, Treweek S, Gagnier JJ et al. (2008) Improving the reporting of pragmatic trials: an extension of the CONSORT statement. BMJ 337, a2390.

20. Kulkarni B, Christian P, LeClerq SC et al. (2010) Determinants of compliance to antenatal micronutrient supplementation and women's perceptions of supplement use in rural Nepal. Public Health Nutr 13, 82-90.

21. Lutsey PL, Dawe D, Villate E et al. (2008) Iron supplementation compliance among pregnant women in Bicol, Philippines. Public Health Nutr 11, 76-82.

22. Hill Z, Kirkwood B, Kendall C et al. (2007) Factors that affect the adoption and maintenance of weekly vitamin A supplementation among women in Ghana. Public Health Nutr 10, 827-833.

23. Knudsen VK, Orozova-Bekkevold I, Rasmussen LB et al. (2004) Low compliance with recommendations on folic acid use in relation to pregnancy: is there a need for fortification? Public Health Nutr 7, 843-850.

24. Kotelchuck M (1994) An evaluation of the Kessner adequacy of prenatal care index and a proposed adequacy of prenatal care utilization index. Am J Public Health 84, 1414-1420. 